\title{
Echocardiographic abnormalities in patients with COPD at their first hospital admission
}

\author{
Xavier Freixa*, Karina Portillo*, Carles Paré, Judith Garcia-Aymerich, \\ Federico P. Gomez, Marta Benet, Josep Roca, Eva Farrero, Jaume Ferrer, \\ Carlos Fernandez-Palomeque, Josep M. Antó, and Joan Albert Barberà on behalf of \\ the PAC-COPD Study Investigators ${ }^{\#}$
}

ABSTRACT: Cardiovascular disease accounts for significant morbidity and mortality in chronic obstructive pulmonary disease (COPD). Its prevalence and mechanisms of association have not been elucidated. The study aimed to assess the prevalence of echocardiographic abnormalities and potential risk factors in patients with COPD at their first exacerbation requiring hospital admission.

Transthoracic echocardiography was prospectively performed in 342 patients (forced expiratory volume in $1 \mathrm{~s} 52 \pm 16 \%$ predicted) 3 months after discharge.

Significant cardiac alterations were present in $64 \%$ of patients; $27 \%$ left- and $48 \%$ right-heart disorders. The most common were right ventricle enlargement $(30 \%)$ and pulmonary hypertension (19\%). Left ventricle enlargement was present in $6 \%$, left ventricle systolic dysfunction in $13 \%$, left ventricle diastolic impairment in $12 \%$ and left atrial dilatation in $29 \%$. Echocardiographic abnormalities were unrelated to COPD severity and were more frequent in patients with selfreported cardiac disease. They were also observed in $63 \%$ of patients with no known cardiac disease or cardiovascular risk factors other than smoking.

We conclude that cardiac abnormalities are highly prevalent in COPD patients at the time of their first severe exacerbation, even in the absence of established cardiac disease or cardiovascular risk factors. Considering the prognostic and therapeutic implications of cardiac comorbidity, echocardiography should be considered in the assessment of patients with clinically significant COPD.

KEYWORDS: Cardiovascular diseases, Doppler echocardiography, pulmonary hypertension, ventricular dysfunction

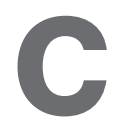
ardiovascular disease is a frequent comorbidity and cause of death in chronic obstructive pulmonary disease (COPD) $[1,2]$. Both conditions share cigarette smoking as a major risk factor for their development, although smoking alone does not fully explain the frequency of this association [3]. Different explanations have been suggested, including systemic inflammation [4], vascular dysfunction [5] and lung hyperinflation [6]. Furthermore, pulmonary hypertension $(\mathrm{PH})$, which is a frequent complication of COPD [7], and the resulting right ventricular dysfunction, are both predictive of survival in COPD [8].

Given the prognostic implications of cardiovascular disease in COPD, its detection could serve as a guide to appropriate treatment and eventually improve survival. The prevalence, development and evolution of cardiovascular comorbidity in the natural history of COPD have not been fully elucidated. This lack of information could be explained by the fact that studies have generally been conducted in small and selected series of cases $[6,9,10]$, restricted either to the right or left chambers [11,12], or by technical difficulties in the echocardiographic assessment of COPD patients.

We hypothesised that a high proportion of COPD patients might present clinically silent echocardiographic abnormalities, and that these cardiac alterations could constitute a clinically relevant trait in COPD.

The present study was undertaken to investigate the prevalence and characteristics of cardiac
AFFILIATIONS

For a full list of the authors' affiliations please see the Acknowledgements.

*These authors contributed equally to the study.

${ }^{\#}$ A full list of the PAC-COPD study investigators and their affiliations can be found in the Acknowledgements.

\section{CORRESPONDENCE}

J.A. Barberà

Servei de Pneumologia

Hospital Clínic

University of Barcelona

Villarroel 170

08036 Barcelona

Spain

E-mail: jbarbera@clinic.ub.es

Received:

Dec 182011

Accepted after revision:

Aug 192012

First published online:

Sept 272012 
abnormalities in a large and representative cohort of COPD patients, assessed at a specific clinical time-point of their natural history: their first hospital admission due to an exacerbation episode. Accordingly, we evaluated the participants in the Phenotype and Characterisation of COPD (PAC-COPD) study, which is a prospective multicentre study that investigated the phenotypic heterogeneity of COPD in a cohort of 342 patients recruited during their first hospital admission due to an exacerbation [13].

\section{METHODS}

\section{Subjects}

Participants were prospectively recruited from January 2004 to March 2006 in nine hospitals in Spain, during their first admission for a COPD exacerbation. The assessments and flow-chart of patient recruitment have been described elsewhere [14]. Briefly, of all the patients admitted to the participating hospitals with a diagnosis of COPD exacerbation, 342 (57\% of those elegible) participated in the study. The diagnosis of COPD was confirmed by forced spirometry at least 3 months after hospital discharge, when patients were clinically stable. COPD severity was defined according to the European Respiratory Society-American Thoracic Society consensus criteria [15].

The protocol was approved by the ethics committees of all the participating hospitals and written informed consent was obtained from all the subjects.

\section{Assessments}

Assessments were performed on clinically stable patients, at least 3 months after discharge. Patients were asked to complete a questionnaire that included: 1) socio-demographic data; 2) lifestyle information; 3) previous treatments and diagnoses; and 4) quality of life (St George's Respiratory Questionnaire). The Charlson index of comorbidity and all previous diagnoses were obtained from medical records.

Presence of cardiovascular risk factors was defined as any of the following: hypertension (self-reported), hypercholesterolaemia $\left(>240 \mathrm{mg} \cdot \mathrm{dL}^{-1}\right)$ or a medical diagnosis of diabetes. Previous cardiac disease was established by patient selfreporting and classified as myocardial infarction, congestive heart failure or non-specified cardiac disorder.

\section{Lung function testing and exercise capacity}

Assessment of pulmonary function included forced spirometry and bronchodilator testing, total body plethysmography, measurement of carbon monoxide diffusing capacity (DLCO) and arterial blood gas analysis. All the procedures were standardised according to current recommendations [16].

\section{Echocardiography}

Doppler echocardiography was performed following a standard protocol. Echocardiograms were recorded in the participating hospitals and sent to the core centre (Hospital Clinic, Barcelona), where uniform reading and analysis were carried out. Standard views were used to obtain parasternal, apical and subcostal views. Each study was classified into three categories, according to the quality of the registry (good, intermediate and poor). The protocol included the measurements recommended by the European Society of Cardiology [17], as follows.
1) Right ventricle dimensions, measured in apical view.

2) Left ventricle size and wall thickness, measured in parasternal view.

3) Left atrial diameter, measured in parasternal view.

4) Aortic root diameters, measured at the sinuses of Valsalva.

5) Left ventricular ejection fraction, assessed by Simpson's rule when adequate two- and four-chamber views were available. In other cases we applied visual estimation ("eye-balling").

6) Evaluation of left and right ventricular diastolic function, which included: 1) maximal peak velocity of early diastolic flow $\left(E_{\max }\right)$, maximal peak velocity of atrial contraction $\left(A_{\max }\right)$, and their ratio $\left(E_{\max } / A_{\max }\right)$, measured over the mitral and tricuspid valves; 2) tissue Doppler imaging measured in the mitral and tricuspid lateral annulus at early diastole (Ea), atrium systole (Aa), and their ratio (Ea/Aa); and 3) The $E_{\max } /$ Ea ratio [18]. Diastolic function of the left ventricle was classified into four categories: I, normal; II, mild; III, moderate; and IV, severe diastolic dysfunction, following the classification proposed by BURSI et al. [19].

7) Mitral, aortic, tricuspid and pulmonary valvular evaluation.

8) Tricuspid regurgitant velocity (TRV) recorded by continuous wave Doppler. Pulmonary hypertension was considered when TRV was $\geqslant 2.8 \mathrm{~m} \cdot \mathrm{s}^{-1}$ [20], and subsequently graded as mild $\left(2.8-3.4 \mathrm{~m} \cdot \mathrm{s}^{-1}\right)$ or moderate-severe $\left(>3.4 \mathrm{~m} \cdot \mathrm{s}^{-1}\right)$.

\section{Data analysis}

Results are expressed as mean \pm SD for continuous variables and as $\mathrm{n}(\%)$ for categorical variables. Comparisons between groups were performed using unpaired t-tests for continuous variables and Chi-squared and Fisher's exact test for categorical variables. Results were stratified according to the presence of previously diagnosed cardiac disease and cardiovascular risk factors. As a sensitivity analysis, we repeated all the computations, this time excluding subjects with poor quality echocardiography. Results were considered statistically significant at a p-value $<0.05$. Statistical analyses were performed using the STATA package, version 10.1 (College Station, TX, USA).

\section{RESULTS}

A total of 342 patients were included in the study. Mean age $\pm S D$ was $67.9 \pm 8.6$ years and 318 patients $(93 \%)$ were males. A wide range of COPD severity was found, although the majority of patients had moderate-to-severe disease, with a mean post-bronchodilator forced expiratory volume in $1 \mathrm{~s}$ (FEV1) of $52.4 \pm 16.2 \%$ of predicted. Characteristics of the subjects and lung function measurements are shown in table 1.

\section{Echocardiographic abnormalities}

The prevalence and characteristics of left and right echocardiographic defects are shown in table 2.

\section{Left heart}

Dilatation of left atrium, followed by hypertrophy of the left ventricle, were the most frequent left heart abnormalities. Impaired left ventricular systolic function (left ventricular ejection fraction (LVEF) $<50 \%$ ) was present in $13.3 \%$ of subjects, although most frequently $(8.9 \%)$ it was only mildly impaired 


\begin{tabular}{|c|c|}
\hline Age years & $67.9 \pm 8.6$ \\
\hline \multicolumn{2}{|l|}{ Sex } \\
\hline Males & $318(93)$ \\
\hline Females & $24(7)$ \\
\hline BMI $\mathbf{k g} \cdot \mathbf{m}^{-2}$ & $28.2 \pm 4.7$ \\
\hline \multicolumn{2}{|l|}{ Smoking status } \\
\hline Current smokers & $109(33)$ \\
\hline Former smokers & $220(66)$ \\
\hline Never smokers & $2(1)$ \\
\hline Systemic hypertension (self-reported) & $123(36)$ \\
\hline Hypercholesterolaemia $>240 \mathrm{mg} \cdot \mathrm{dL}^{-1}$ & $78(23)$ \\
\hline Diabetes mellitus (physician-diagnosed) & $62(18)$ \\
\hline Myocardial infarction (physician-diagnosed) & $36(11)$ \\
\hline Stroke (physician-diagnosed) & $12(4)$ \\
\hline Peripheral vascular disease (physician-diagnosed) & $37(11)$ \\
\hline Renal insufficiency (physician-diagnosed) & $20(6)$ \\
\hline \multicolumn{2}{|l|}{ COPD severity } \\
\hline I: mild (FEV1 $\geqslant 80 \%$ pred) & $19(6)$ \\
\hline II: moderate (FEV1 50\%-79\% pred) & $164(48)$ \\
\hline III: severe (FEV1 30\%-49\% pred) & $132(39)$ \\
\hline IV: very severe (FEV $1<30 \%$ pred) & $27(8)$ \\
\hline Post-BD FVC \% pred & $68.7 \pm 16.2$ \\
\hline Post-BD FEV 1 \% pred & $52.4 \pm 16.2$ \\
\hline Post-BD FEV $1 /$ FVC $\%$ pred & $53.4 \pm 11.9$ \\
\hline DLco \% pred & $65.2 \pm 20.7$ \\
\hline $\mathrm{PaO}_{2} \mathrm{mmHg}$ & $74.3 \pm 10.6$ \\
\hline $\mathrm{PaCO}_{2} \mathrm{mmHg}$ & $41.8 \pm 5.3$ \\
\hline TLC \% pred & $100.4 \pm 18.4$ \\
\hline IC \% pred & $62.8 \pm 18.5$ \\
\hline IC/TLC & $0.31 \pm 0.10$ \\
\hline
\end{tabular}

Data are presented as mean \pm SD or $n(\%)$. Total $n=342$ patients. BMI: body mass index; COPD: chronic obstructive pulmonary disease; FEV1: forced expiratory volume in $1 \mathrm{~s}$; \% pred: \% predicted; BD: bronchodilator; FVC: forced vital capacity; $\mathrm{DLCO}$ : diffusing capacity of the lung for carbon monoxide; $\mathrm{PaO}_{2}$ : arterial oxygen tension; $\mathrm{PaCO}_{2}$ : arterial carbon dioxide tension; TLC: total lung capacity; IC: inspiratory capacity.

(LVEF 40-50\%). In the remaining 4.4\% it ranged between 30 and $40 \%$. Abnormal left ventricular segmentary wall motion was detected in $4.1 \%$ of patients and only one-third of patients with this abnormality reported previous ischaemic cardiopathy. Normal or grade I left ventricular diastolic dysfunction was seen in only $37.9 \%$ of patients.

Overall, of the 278 patients in which the left ventricle could be fully assessed, 74 (27\%) presented significant abnormalities (table 3). There were no differences with respect to sociodemographic or clinical variables between these 278 patients and those in which the left ventricle could not be fully assessed.

\section{Right heart}

Right ventricular enlargement was the most common echocardiographic disorder (29.9\% of patients). Transtricuspid flow recorded by pulsed wave Doppler showed signs of right ventricular diastolic dysfunction, as shown by the higher $\mathrm{E}_{\max }$ higher $A_{\max }$, and lower $E_{\max } / A_{\max }$ ratio than those found in

\section{TABLE 2 Echocardiographic measurements and prevalence of abnormalities}

\begin{tabular}{|c|c|c|}
\hline Characteristic & Subjects & Measurements \\
\hline \multicolumn{3}{|l|}{ Left heart } \\
\hline \multicolumn{3}{|l|}{ Dimensions } \\
\hline \multicolumn{3}{|l|}{ Left atrium } \\
\hline Diameter mm & 279 & $37.8 \pm 6.4$ \\
\hline Abnormal value $(\geqslant 40 \mathrm{~mm}) \%$ & & $29(24-35)$ \\
\hline \multicolumn{3}{|l|}{ Left ventricle } \\
\hline End-diastolic diameter mm & 293 & $50.6 \pm 5.6$ \\
\hline Abnormal value ${ }^{\#} \%$ & & $6(3-8)$ \\
\hline Wall thickness mm & 291 & $10.7 \pm 1.5$ \\
\hline Abnormal value $(\geqslant 12 \mathrm{~mm}) \%$ & & $26(21-31)$ \\
\hline \multicolumn{3}{|l|}{ Ventricular function } \\
\hline Systolic function & 294 & \\
\hline LV ejection fraction \% & & $59.1 \pm 8.9$ \\
\hline Abnormal value ( $\leqslant 50 \%) \%$ & & $13(9-17)$ \\
\hline Diastolic function & 282 & \\
\hline Normal or grade I & & $107(38)$ \\
\hline Grade ॥ & & $141(50)$ \\
\hline Grade III & & $23(8)$ \\
\hline Grade IV & & $11(4)$ \\
\hline \multicolumn{3}{|l|}{ Right heart } \\
\hline \multicolumn{3}{|l|}{ Dimensions } \\
\hline \multicolumn{3}{|l|}{ Right ventricle } \\
\hline Mid end-diastolic diameter $\mathrm{mm}$ & 234 & $31.6 \pm 3.8$ \\
\hline Abnormal value $(>33 \mathrm{~mm}) \%$ & & $30(24-36)$ \\
\hline Inferior cava vein & 191 & \\
\hline Mid diameter at rest mm & & $12.4 \pm 4.0$ \\
\hline Abnormal value $(\geqslant 20 \mathrm{~mm}) \%$ & & $6(4-8)$ \\
\hline \multicolumn{3}{|l|}{ Ventricular function } \\
\hline \multicolumn{3}{|l|}{ Diastolic function } \\
\hline$E_{\max }$ tricuspid $\mathrm{cm} \cdot \mathrm{s}^{-1}$ & 270 & $48.6 \pm 12.9$ \\
\hline$A_{\max }$ tricuspid $\mathrm{cm} \cdot \mathrm{s}^{-1}$ & 265 & $51.4 \pm 15.9$ \\
\hline E/A tricuspid & 265 & $1.0 \pm 0.45$ \\
\hline $\mathrm{E} / \mathrm{Ea}_{\max }$ tricuspid & 211 & $5.0 \pm 2.30$ \\
\hline $\mathrm{Ea}_{\max }$ tricuspid $\mathrm{cm} \cdot \mathrm{s}^{-1}$ & 224 & $11.3 \pm 4.7$ \\
\hline $\mathrm{Aa}_{\max }$ tricuspid $\mathrm{cm} \cdot \mathrm{s}^{-1}$ & 215 & $17.3 \pm 6.9$ \\
\hline Ea/Aa tricuspid & 215 & $0.7 \pm 0.5$ \\
\hline \multicolumn{3}{|l|}{ Assessment of pulmonary hypertension } \\
\hline Transtricuspid regurgitant velocity $\mathrm{m} \cdot \mathrm{s}^{-1}$ & 179 & $2.39 \pm 0.55$ \\
\hline Abnormal value $\left(\geqslant 2.8 \mathrm{~m} \cdot \mathrm{s}^{-1}\right) \%$ & & $19(13-25)$ \\
\hline $\begin{array}{l}\text { Estimated systolic pulmonary } \\
\text { artery pressure } \mathrm{mmHg}\end{array}$ & & $34.0 \pm 10.1$ \\
\hline
\end{tabular}

Data are presented as $n$, mean \pm SD, \% $(95 \% \mathrm{Cl})$, or $n(\%)$. LV: left ventricular; $E_{\max }$ : maximal peak velocity of early diastolic flow; $A_{\max }$ : maximal peak velocity of atrial contraction; $E / A$ : $E_{\max } / A_{\max }$; $E / E_{\max }$ : $E_{\max } / E_{\max } ; \mathrm{Ea}_{\max }$ : maximum mitral and tricuspid lateral annulus at early diastole; $\mathrm{Aa}_{\max }$ : maximum mitral and tricuspid lateral annulus at atrium systole. ${ }^{*}$ : $>59 \mathrm{~mm}$ for males and $>53 \mathrm{~mm}$ for females; ": left ventricular ejection fraction assessed by Simpsons rule in 243 patients $(82.6 \%)$ and corrected by visual estimation in 51 (17.3\%).

healthy subjects [21]. Moreover, measurements of lateral tricuspid tissue by Doppler imaging were also consistent with right ventricular diastolic impairment with low $\mathrm{Ea}$, high $\mathrm{Aa}$, and low $\mathrm{Ea} / \mathrm{Aa}$ ratio. 
TABLE 3 Presence of echocardiographic disorders according to previous cardiac disease or presence of cardiovascular (CV) risk factors

\begin{tabular}{|c|c|c|c|c|c|c|}
\hline & \multirow{3}{*}{$\begin{array}{l}\text { All subjects } \\
\mathrm{n}=\mathbf{3 4 2}\end{array}$} & \multicolumn{3}{|c|}{ Previous cardiac disease $^{\#}$} & \multicolumn{2}{|c|}{ Comparisons } \\
\hline & & \multirow[b]{2}{*}{ Group $1 \mathrm{n}=80$} & \multicolumn{2}{|c|}{ No } & \multirow{2}{*}{$\begin{array}{l}\text { Group } 1 \text { versus } \\
2 / 3 \text { p-value }\end{array}$} & \multirow{2}{*}{$\begin{array}{c}\text { Group } 2 \text { versus } \\
3 \text { p-value }\end{array}$} \\
\hline & & & $\begin{array}{c}\text { CV risk factors } \\
\text { (group 2) } \\
n=139\end{array}$ & $\begin{array}{c}\text { No CV risk } \\
\text { factors (group 3) } \\
n=114\end{array}$ & & \\
\hline \multicolumn{7}{|l|}{ Left Ventricle } \\
\hline Enlarged end-diastolic diameter" ( $n=293)$ & $17(6)$ & $9(14)$ & $5(4)$ & $3(3)$ & 0.001 & 0.700 \\
\hline Diastolic dysfunction grade $\geqslant 3(n=282)$ & $34(12)$ & $8(14)$ & $11(9)$ & $15(15)$ & 0.632 & 0.127 \\
\hline Ejection fraction $\leqslant 50 \%(n=294)$ & $39(13)$ & $17(27)$ & $10(8)$ & $12(12)$ & 0.000 & 0.291 \\
\hline $\begin{array}{l}\text { Global left ventricle impairment (any of the } \\
\text { above) }(n=278)\end{array}$ & $74(27)$ & $27(47)$ & $22(19)$ & $25(27)$ & 0.000 & 0.166 \\
\hline $\begin{array}{l}\text { Transtricuspid regurgitant velocity } \geqslant 2.8 \mathrm{~m} \cdot \mathrm{s}^{-1} \\
\qquad(\mathrm{n}=179)\end{array}$ & $34(19)$ & $7(16)$ & $17(24)$ & $10(17)$ & 0.535 & 0.348 \\
\hline $\begin{array}{l}\text { Global right heart impairment (any of the } \\
\text { above) }(n=181)\end{array}$ & $87(48)$ & $22(54)$ & $38(50)$ & $27(44)$ & 0.437 & 0.504 \\
\hline Global left and/or right impairment $(n=201)$ & $129(64)$ & $36(77)$ & $50(60)$ & $43(63)$ & 0.048 & 0.707 \\
\hline
\end{tabular}

Data are shown as n (\%). ${ }^{*}$ : myocardial infarction in $9.9 \%$, chronic heart failure in $5 \%$, and unspecified cardiac disorder in $8.8 \%$; ${ }^{\bullet}>59$ mm for males and $>53$ mm for females.

Maximal TRV could be assessed in $62 \%$ of patients, showing an abnormal value $\left(\geqslant 2.8 \mathrm{~m} \cdot \mathrm{s}^{-1}\right)$ in $19 \%$, consistent with $\mathrm{PH}$, although of those patients $16.2 \%$ had slightly elevated values, whereas moderate or severe values $\left(>3.4 \mathrm{~m} \cdot \mathrm{s}^{-1}\right)$ were observed in only $2.8 \%$.

Of the 181 patients in which the right heart could be adequately assessed, 87 (48\%) presented abnormalities (table 3).

\section{Valvular disease}

Moderate or severe left valvulopathy was present in $8.7 \%$ of patients: mitral regurgitation in $3.1 \%$, aortic regurgitation in $5.5 \%$ and aortic stenosis in $1.2 \%$. Only three of the eight patients with mitral insufficiency presented functional mitral regurgitation.

\section{Echocardiographic abnormalities and cardiovascular risk factors}

To investigate whether echocardiographic findings were associated with previous cardiac disease and/or cardiovascular risk factors, we assessed the proportion of patients with major echocardiographic disorders according to the presence/ absence of cardiovascular risk factors (except smoking, since $99 \%$ of patients were current or former smokers), and/or selfreported previous cardiac disease.

As anticipated, patients with previous cardiac disorders had a greater prevalence of left heart abnormalities detected by echocardiography, whereas the prevalence of right heart abnormalities did not differ between the subgroups (table 3). 43 $(63 \%)$ patients with COPD, without previously diagnosed heart disease and free of cardiovascular risk factors other than cigarette smoking, had significant echocardiographic abnormalities; in $27 \%$ these affected the left ventricle and in $44 \%$ the right heart.

\section{Echocardiographic abnormalities and COPD severity}

The potential association between echocardiographic abnormalities and COPD severity was also analysed. Table 4 shows the percentage of patients with echocardiographic abnormalities according to COPD severity. No association was observed between the degree of airflow obstruction, the distance covered in the 6-min walk test or the St George's Respiratory Questionnaire and the presence of echocardiographic abnormalities. Furthermore, we did not find any significant association between arterial oxygen tension $\left(\mathrm{PaO}_{2}\right)$ and the presence of left ventricle impairment $(74.2 \pm 1.2 \mathrm{mmHg}$ and $74.4 \pm 0.8 \mathrm{mmHg}$, in patients with and without left ventricle impairment; $\mathrm{p}=0.88)$. $\mathrm{PH}$ was more prevalent in patients with severe airflow obstruction (FEV1 $\leqslant 50 \%$ pred) $(32.9 \%)$ than in patients with FEV $1>50 \%$ pred $(7.2 \%)(\mathrm{p}<0.001)$. Patients with PH had greater right ventricle diameter $(33.9 \pm 4.5 \mathrm{~mm})$ than those without PH $(31.2 \pm 3.4 \mathrm{~mm} ; \mathrm{p}<0.001)$.

A total of $229(67.7 \%)$ and 262 (77.5\%) patients had been previously treated with anticholinergic or beta-agonist bronchodilators, respectively. No relationship was found between echocardiographic abnormalities and previous use of these agents. 


\begin{tabular}{|c|c|c|c|}
\hline \multirow[t]{2}{*}{ TABLE 4} & \multicolumn{3}{|c|}{$\begin{array}{l}\text { Patients with echocardiographic abnormalities } \\
\text { according to chronic obstructive pulmonary } \\
\text { disease severity }\end{array}$} \\
\hline & $\begin{array}{c}\text { Left heart } \\
\text { abnormalities }\end{array}$ & $\begin{array}{c}\text { Right heart } \\
\text { abnormalities }\end{array}$ & $\begin{array}{l}\text { Left and/or right } \\
\text { heart abnormalities }\end{array}$ \\
\hline \multicolumn{4}{|l|}{ FEV 1} \\
\hline$\leqslant 50 \%$ pred & $23(30)$ & $40(42)$ & 47 (62) \\
\hline$>50 \%$ pred & $29(30)$ & $41(53)$ & $53(55)$ \\
\hline \multicolumn{4}{|l|}{$\begin{array}{r}\text { 6-min walk } \\
\text { distance }\end{array}$} \\
\hline$\leqslant 440 \mathrm{~m}$ & $22(30)$ & 37 (49) & $45(61)$ \\
\hline$>440 \mathrm{~m}$ & $24(29)$ & $37(45)$ & $47(57)$ \\
\hline \multicolumn{4}{|l|}{ SGRQ } \\
\hline$\leqslant 33$ & $25(28)$ & $44(49)$ & $54(60)$ \\
\hline$>33$ & 27 (33) & 37 (45) & $46(57)$ \\
\hline
\end{tabular}

Data are presented as $n(\%) . n=173$ patients who underwent complete echocardiographic assessment. FEV1: forced expiratory volume in $1 \mathrm{~s} ; \%$ pred: \% predicted; SGRQ: St Georg's Respiratory Questionnaire.

Sensitivity analysis excluding subjects with poor quality echocardiography yielded similar results.

\section{DISCUSSION}

The results of the present study, conducted in one of the largest cohorts of COPD patients assessed by echocardiography to date, show an elevated prevalence of both left and right cardiac disorders at the time of their first hospital admission due to an exacerbation episode. The proportion of patients presenting cardiac disorders remained high even after excluding those with cardiovascular risk factors, and it was unrelated to COPD severity.

Cardiovascular disease is a frequent cause of mortality in COPD. Roughly $30 \%$ of patients die from a cardiovascular cause $[1,2,22]$. A better understanding of the association between COPD and cardiovascular disease should help improve the outcome, particularly if cardiovascular disease could be identified earlier and/or prevented [23]. Previous echocardiographic studies in COPD present limitations because of their retrospective design, their reduced number of subjects, their partial echocardiographic analysis or their potential selection biases [9, 11, 12, 24]. To overcome these difficulties, we prospectively explored COPD patients at a well-defined and relevant time-point of their clinical evolution, i.e. their first hospital admission due to an exacerbation, selecting them from the population admitted in nine hospitals during a defined period of time and performing a comprehensive echocardiographic assessment [14]. Thus, the results of the present study are representative of patients with clinically relevant COPD.

The study shows a high prevalence $(64 \%)$ of significant echocardiographic abnormalities, in $27 \%$ of cases affecting the left heart and in $48 \%$ the right heart.

\section{Left heart impairment}

Enlargement of the left atrium and left ventricular hypertrophy were present in $20-30 \%$ of patients, whereas left ventricular systolic dysfunction (LVSD) was identified in $13.3 \%$, albeit generally of mild intensity. The prevalence of left heart abnormalities previously reported in COPD patients varies widely, from 0 to $32 \%$ [11, 12], depending on whether the study was performed on "selected" patients with no history of coronary artery disease or on unselected subjects. The prevalence of LVSD in our cohort was similar to that recently reported by MACCHIA et al. [12] (13.7\%) and is in keeping with the emerging evidence that unrecognised left heart failure is common in stable COPD patients, as shown by RUTTEN et al. [25]. Our study complements these previous observations by showing similar results in a cohort of patients with COPD who already required hospitalisation for an exacerbation episode. Since most of the detected cardiac abnormalities were of mild severity, the clinical implications of these findings are unclear. Although a potential lower threshold for congestive heart failure in patients with systolic or diastolic dysfunction might be anticipated, the progression of echocardiographic abnormalities, the need for specific management and the impact on clinical outcome in COPD patients warrant future evaluation.

In our study, almost 30\% of patients with LVSD presented left ventricle wall motion abnormalities, strongly suggesting ischaemic heart disease as the underlying mechanism, even though the disease had only been previously diagnosed in onethird of those patients. Another important finding was the high prevalence of left ventricular diastolic dysfunction (62\%) in the present cohort. Although the age and characteristics of the population might explain the high prevalence of mild dysfunction $(50 \%)$ [26], it is worth noting that $12 \%$ of patients presented moderate (grade 3) or severe (grade 4) diastolic impairment.

Recent studies have suggested potential mechanisms that may explain the association between left ventricular dysfunction and COPD. First, the vascular dysfunction of systemic arteries, assessed by means of flow-mediated vasodilatation [27], arterial stiffness [5] or carotid intima-media thickness [28], is more prevalent in COPD and could explain the association with subclinical left ventricle abnormalities. Secondly, the presence of emphysema has been related to impaired left ventricle filling [29]. It is conceivable that hyperinflation and increased intrathoracic pressures produced by emphysema may impair cardiac function by decreasing biventricular preload and increasing left ventricular afterload [30]. Thirdly, chronic hypoxaemia might also affect myocardial relaxation [24], although in our study no relationship was shown between $\mathrm{PaO}_{2}$ and left ventricle impairment. Finally, the influence of chronic right ventricular pressure overload on the interventricular septum may also jeopardize left ventricular filling as a result of abnormal left ventricle torsion and impaired longitudinal and circumferential strain [31]. Whatever the mechanism, it is apparent that the presence of left ventricular dysfunction has a negative impact on COPD survival [11]. Accordingly, the early identification of such comorbidity might help improve patient outcome. In fact, a subgroup of COPD patients who combined mild airflow obstruction with a high proportion of obesity, cardiovascular disorders and diabetes was identified in the PAC-COPD cohort. Interestingly, these patients required more hospital admissions as a result of cardiovascular disease during the follow-up [13]. 


\section{Right heart impairment}

We observed right ventricular enlargement in 30\% of patients, and this was more pronounced in those with $\mathrm{PH}$. Assessment of the right ventricle is important in COPD because its enlargement or dysfunction is associated with limited exercise capacity and a poorer prognosis [8]. Subclinical right ventricular dysfunction detected by echocardiography might be present in patients with mild airflow obstruction [10], while right ventricular hypertrophy, assessed by magnetic resonance, has been shown in COPD patients without PH [32]. Overall, these observations suggest that right ventricle morphological and functional changes could be early signs of pressure overload developing in the initial disease stages.

Tricuspid regurgitation may not always be present in COPD, limiting the possibility of estimating systolic pulmonary artery pressure (PAP). In our cohort we were able to determine TRV and hence estimate systolic PAP in $62 \%$ of cases, which is within the best range reported in the literature.

The prevalence of $\mathrm{PH}$ in the whole cohort was 19\%, being much more prevalent in patients with severe disease $(33 \%)$ than in those with mild disease $(7 \%)$. Although $\mathrm{PH}$ is a frequent complication in the natural history of COPD, its prevalence in the whole spectrum of the disease remains unclear because the majority of studies have been conducted in patients with advanced disease [7]. The magnitude of PH was mild in the majority of cases and in only 3\% of patients did TRV exceed $3.4 \mathrm{~m} \cdot \mathrm{s}^{-1}$, which is equivalent to a systolic PAP $>55 \mathrm{mmHg}$, a value close to the estimated prevalence of out-of-proportion $\mathrm{PH}$ in COPD [33].

\section{Influence of cardiovascular risk factors and disease severity}

As anticipated, a previous diagnosis of cardiac disease was associated with greater prevalence of echocardiographic abnormalities in the left heart, but the lack of association between the presence of cardiovascular risk factors and echocardiographic abnormalities was unexpected. In this cohort the proportion of cardiac impairment remained high even after excluding patients with cardiovascular risk factors or previous cardiac disease. This observation suggests that COPD per se could be a risk factor for the development of heart disorders. Smoking, a risk factor for both COPD and cardiovascular disease, could explain such an association. However, as discussed above, increasing evidence suggests that COPD may induce vascular damage by mechanisms independent of cigarette smoking $[3,4]$ and that lung hyperinflation may directly affect ventricular function [6, 29].

In the present cohort the severity of airflow obstruction was not associated with the prevalence of heart disease. This finding concurs with the lack of association between COPD severity and cardiac comorbidity reported in the large ECLIPSE cohort [34] and could lead to the hypothesis that it is the presence of COPD, rather than its severity, that favours the development of cardiovascular disease. In contrast, the presence of echocardiographic abnormalities did not appear to modify exercise tolerance or quality of life. Furthermore, we did not find any association between the use of bronchodilators and echocardiographic abnormalities, in line with recent reanalyses of large clinical trials [35].
The study has some limitations. First, the absence of a control group limits a definite assessment of the role of COPD in the pathogenesis of cardiac disorders. Secondly, the range of COPD severity is somewhat restricted, limiting the extrapolation of current findings to the whole disease spectrum. Yet, we prospectively assessed patients at a very specific and clinically relevant time-point, i.e. their first hospital admission due to an exacerbation, and carefully screened patients who satisfied the diagnosis of COPD in a number of hospitals with different clinical practices. This allowed us to avoid potential selection biases that could arise from other methods of recruitment. Thirdly, the study had a cross-sectional design, so no causal relationships with clinical outcomes could be established. Fourthly, as a result of a suboptimal echocardiographic window, the right ventricle was only measurable in 234 patients. Fifth, left atrium diameters and not left atrium indexed volumes were measured. Despite the greater diagnostic accuracy of indexed volumes, left atrium diameters provide valuable information and might be less prone to misevaluation in patients with a suboptimal echocardiographic window. Finally, the presence of previous cardiovascular disease was dependent on patient selfreporting, thus we cannot exclude the under-reporting of preexisting cardiovascular disorders.

In conclusion, this large, prospective, multicentre, comprehensive echocardiographic study shows that cardiac disorders are highly prevalent in patients with moderate-to-severe COPD, even among those without cardiovascular risk factors other than cigarette smoking. Whereas right heart abnormalities could be anticipated, such a high prevalence of left heart abnormalities is a novel and unexpected finding that was unrelated to disease severity. Accordingly, the implementation of echocardiography in the evaluation of COPD patients should be considered, since it might help detect unrecognised cardiac disorders and establish adequate treatment that may potentially improve patient prognosis.

\section{SUPPORT STATEMENT}

Supported by grants from the Fondo de Investigación Sanitaria (PI020541, PI052486, PI052302); Agència d'Avaluació de Tecnologia i Recerca Mèdiques (AATRM 035/20/02); Spanish Society of Pulmonology and Thoracic Surgery (SEPAR 2008/732); Catalan Foundation of Pulmonology (FUCAP 2008); Red RESPIRA (RTIC C03/11); Red RCESP (RTIC C03/09); Fundació La Marató de TV3 (041110); DURSI (2005SGR00392); and an unrestricted educational grant from Novartis Farmacéutica, Spain. CIBERESP and CIBERES are funded by the Instituto de Salud Carlos III, Ministry of Scientific Research and Innovation, Spain. Judith Garcia-Aymerich was the recipient of a researcher contract from the Instituto de Salud Carlos III (CP05/00118).

\section{STATEMENT OF INTEREST None declared.}

\section{ACKNOWLEDGEMENTS}

This work was performed as part of the doctoral programme in Internal Medicine at the Universitat Autónoma de Barcelona.

The authors' affiliations are as follows. X. Freixa: Depts of Cardiology, Hospital Clínic-IDIBAPS, University of Barcelona, Barcelona; K. Portillo: Pulmonary Medicine, Hospital Clínic-IDIBAPS, University of Barcelona, Barcelona; C. Paré: Depts of Cardiology, Hospital Clínic-IDIBAPS, University of Barcelona, Barcelona; J. Garcia-Aymerich: Centre for Research in Environmental Epidemiology, Barcelona, Municipal Institute of Medical Research, Hospital del Mar, Barcelona, Dept of Experimental and Health Sciences, Universitat Pompeu Fabra, Barcelona and Centro de 
Investigación en Red de Epidemiologia y Salud Pública (CIBERESP), Madrid; F.P. Gomez: Pulmonary Medicine, Hospital Clínic-IDIBAPS, University of Barcelona, Barcelona and Centro de Investigación en Red de Enfermedades Respiratorias (CIBERES), Barcelona; M. Benet: Centre for Research in Environmental Epidemiology, Barcelona, Municipal Institute of Medical Research, Hospital del Mar, Barcelona and Centro de Investigación en Red de Epidemiologia y Salud Pública (CIBERESP), Madrid; J. Roca: Pulmonary Medicine, Hospital Clínic-IDIBAPS, University of Barcelona, Barcelona and Centro de Investigación en Red de Enfermedades Respiratorias (CIBERES), Barcelona; E. Farrero: Dept of Pulmonary Medicine, Hospital de Bellvitge, Barcelona; J. Ferrer: Centro de Investigación en Red de Enfermedades Respiratorias (CIBERES), Barcelona and Dept of Pulmonary Medicine, Hospital Vall d'Hebron, Barcelona; C. Fernandez-Palomeque: Dept of Cardiology, Hospital Universitari Son Dureta, Palma de Mallorca; J.M. Antó: Centre for Research in Environmental Epidemiology, Barcelona, Municipal Institute of Medical Research, Hospital del Mar, Barcelona, Dept of Experimental and Health Sciences, Universitat Pompeu Fabra, Barcelona and Centro de Investigación en Red de Epidemiologia y Salud Pública (CIBERESP), Madrid; J.A. Barberà: Pulmonary Medicine, Hospital Clínic-IDIBAPS, University of Barcelona, Barcelona and Centro de Investigación en Red de Enfermedades Respiratorias (CIBERES), Barcelona, Spain.

List of investigators of the Phenotype and Course of COPD (PACCOPD) Study.

Centre for Research in Environmental Epidemiology (CREAL), Barcelona: Josep M. Antó (Principal Investigator), Judith GarciaAymerich (project coordinator), Marta Benet, Jordi de Batlle, Ignasi Serra, David Donaire-Gonzalez, Stefano Guerra; Hospital del MarIMIM, Barcelona: Joaquim Gea (centre coordinator), Eva Balcells, Àngel Gayete, Mauricio Orozco-Levi, Ivan Vollmer, Lluís Molina; Hospital Clínic-Institut d'Investigacions Biomèdiques August Pi i Sunyer (IDIBAPS), Barcelona: Joan Albert Barberà (centre coordinator), Federico P. Gómez, Carles Paré, Josep Roca, Robert Rodriguez-Roisin, Xavier Freixa, Diego A. Rodriguez, Elena Gimeno, Karina Portillo; Hospital General Universitari Vall dHebron, Barcelona: Jaume Ferrer (centre coordinator), Jordi Andreu, Esther Pallissa, Esther Rodríguez, Herminio García del Castillo, Consuelo Orihuela; Hospital de la Santa Creu i Sant Pau, Barcelona: Pere Casan (centre coordinator), Rosa Güell, Ana Giménez, Francesc Carreras; Hospital Universitari Germans Trias i Pujol, Badalona: Eduard Monsó (centre coordinator), Alicia Marín, Josep Morera, Jorge López; Hospital Universitari de Bellvitge, L'Hospitalet de Llobregat: Eva Farrero (centre coordinator), Joan Escarrabill, Carmen Ugartemendia; Hospital de Sabadell, Corporació Parc Taulí, Institut Universitari Parc Taulí (Universitat Autònoma de Barcelona), Sabadell: Antoni Ferrer (centre coordinator), Antonio Martínez; Hospital Universitari Son Dureta, Palma de Mallorca: Jaume Sauleda (centre coordinator), Àlvar G. Agustí, Bernat Togores, Carlos Fernández-Palomeque; Hospital de Cruces, Barakaldo: Juan Bautista Gáldiz (centre coordinator), Lorena López, David Rodrigo; Hospital General Universitari, València: José Belda.

\section{REFERENCES}

1 Berry CE, Wise RA. Mortality in COPD: causes, risk factors, and prevention. COPD 2010; 7: 375-382.

2 Ekstrom MP, Wagner P, Strom KE. Trends in cause-specific mortality in oxygen-dependent chronic obstructive pulmonary disease. Am J Respir Crit Care Med 2011; 183: 1032-1036.

3 Calverley PM, Scott S. Is airway inflammation in chronic obstructive pulmonary disease (COPD) a risk factor for cardiovascular events? COPD 2006; 3: 233-242.

4 Sinden NJ, Stockley RA. Systemic inflammation and comorbidity in COPD: a result of 'overspill' of inflammatory mediators from the lungs? Review of the evidence. Thorax 2010; 65: 930-936.
5 Mills NL, Miller JJ, Anand A, et al. Increased arterial stiffness in patients with chronic obstructive pulmonary disease: a mechanism for increased cardiovascular risk. Thorax 2008; 63: 306-311.

6 Watz H, Waschki B, Meyer T, et al. Decreasing cardiac chamber sizes and associated heart dysfunction in COPD: role of hyperinflation. Chest 2010; 138: 32-38.

7 Barbera JA, Peinado VI, Santos S. Pulmonary hypertension in chronic obstructive pulmonary disease. Eur Respir J 2003; 21: 892-905.

8 Burgess MI, Mogulkoc N, Bright-Thomas RJ, et al. Comparison of echocardiographic markers of right ventricular function in determining prognosis in chronic pulmonary disease. I Am Soc Echocardiogr 2002; 15: 633-639.

9 Schena M, Clini E, Errera D, et al. Echo-Doppler evaluation of left ventricular impairment in chronic cor pulmonale. Chest 1996; 109: 1446-1451.

10 Sabit R, Bolton CE, Fraser AG, et al. Sub-clinical left and right ventricular dysfunction in patients with COPD. Respir Med 2010; 104: 1171-1178.

11 Flu WJ, van Gestel YR, van Kuijk JP, et al. Co-existence of COPD and left ventricular dysfunction in vascular surgery patients. Respir Med 2010; 104: 690-696.

12 Macchia A, Moncalvo JJ, Kleinert M, et al. Unrecognized ventricular dysfunction in COPD. Eur Respir J 2012; 39: 51-58.

13 Garcia-Aymerich J, Gomez FP, Benet M, et al. Identification and prospective validation of clinically relevant chronic obstructive pulmonary disease (COPD) subtypes. Thorax 2011; 66: 430-437.

14 Balcells E, Anto JM, Gea J, et al. Characteristics of patients admitted for the first time for COPD exacerbation. Respir Med 2009; 103: 1293-1302.

15 Celli BR, MacNee W. Standards for the diagnosis and treatment of patients with COPD: a summary of the ATS/ERS position paper. Eur Respir J 2004; 23: 932-946.

16 Pellegrino R, Viegi G, Brusasco V, et al. Interpretative strategies for lung function tests. Eur Respir J 2005; 26: 948-968.

17 Lang RM, Bierig M, Devereux RB, et al. Recommendations for chamber quantification. Eur J Echocardiogr 2006; 7: 79-108.

18 Nagueh SF, Lakkis NM, Middleton KJ, et al. Doppler estimation of left ventricular filling pressures in patients with hypertrophic cardiomyopathy. Circulation 1999; 99: 254-261.

19 Bursi F, Weston SA, Redfield MM, et al. Systolic and diastolic heart failure in the community. JAMA 2006; 296: 2209-2216.

20 Galie N, Hoeper MM, Humbert M, et al. Guidelines for the diagnosis and treatment of pulmonary hypertension. Eur Respir J 2009; 34: 1219-1263.

21 Moustapha A, Lim M, Saikia S, et al. Interrogation of the tricuspid annulus by Doppler tissue imaging in patients with chronic pulmonary hypertension: implications for the assessment of rightventricular systolic and diastolic function. Cardiology 2001; 95: 101-104

22 Calverley PM, Anderson JA, Celli B, et al. Salmeterol and fluticasone propionate and survival in chronic obstructive pulmonary disease. N Engl J Med 2007; 356: 775-789.

23 Fabbri LM, Beghe B, Agusti A. Cardiovascular mechanisms of death in severe COPD exacerbation: time to think and act beyond guidelines. Thorax 2011; 66: 745-747.

24 Funk GC, Lang I, Schenk P, et al. Left ventricular diastolic dysfunction in patients with COPD in the presence and absence of elevated pulmonary arterial pressure. Chest 2008; 133: 1354-1359.

25 Rutten FH, Cramer MJ, Grobbee DE, et al. Unrecognized heart failure in elderly patients with stable chronic obstructive pulmonary disease. Eur Heart J 2005; 26: 1887-1894.

26 Curkendall SM, DeLuise C, Jones JK, et al. Cardiovascular disease in patients with chronic obstructive pulmonary disease, Saskatchewan Canada cardiovascular disease in COPD patients. Ann Epidemiol 2006; 16: 63-70. 
27 Eickhoff P, Valipour A, Kiss D, et al. Determinants of systemic vascular function in patients with stable chronic obstructive pulmonary disease. Am J Respir Crit Care Med 2008; 178: 1211-1218.

28 Iwamoto H, Yokoyama A, Kitahara Y, et al. Airflow limitation in smokers is associated with subclinical atherosclerosis. Am J Respir Crit Care Med 2009; 179: 35-40.

29 Barr RG, Bluemke DA, Ahmed FS, et al. Percent emphysema, airflow obstruction, and impaired left ventricular filling. $N$ Engl $J$ Med, 362: 217-227.

30 Jorgensen K, Muller MF, Nel J, et al. Reduced intrathoracic blood volume and left and right ventricular dimensions in patients with severe emphysema: an MRI study. Chest 2007; 131: 1050-1057.
31 Puwanant S, Park M, Popovic ZB, et al. Ventricular geometry, strain, and rotational mechanics in pulmonary hypertension. Circulation, 121: 259-266.

32 Vonk-Noordegraaf A, Marcus JT, Holverda S, et al. Early changes of cardiac structure and function in COPD patients with mild hypoxemia. Chest 2005; 127: 1898-1903.

33 Chaouat A, Bugnet AS, Kadaoui N, et al. Severe pulmonary hypertension and chronic obstructive pulmonary disease. Am J Respir Crit Care Med 2005; 172: 189-194.

34 Agusti A, Calverley PM, Celli B, et al. Characterisation of COPD heterogeneity in the ECLIPSE cohort. Respir Res 2010; 11: 122.

35 Tashkin DP. Long-acting anticholinergic use in chronic obstructive pulmonary disease: efficacy and safety. Curr Opin Pulm Med 2010; 16: 97-105. 